\title{
ARTIFICIAL AURORAS IN THE UPPER ATMOSPHERE 1. ELECTRON BEAM INJECTIONS
}

\author{
J. L. Burch ${ }^{1}$, S. B. Mende ${ }^{2}$, N. Kawashima ${ }^{3}$, W. T. Roberts ${ }^{4}$, W. W. L. Taylor ${ }^{5}$, \\ T. Neubert ${ }^{6}$, W. C. Gibson ${ }^{1}$, J. A. Marshall ${ }^{1}$, and G. R. Swenson ${ }^{2}$
}

\begin{abstract}
Artificial electron beams from the Space Experiments with Particle Accelerators (SEPAC) on the ATLAS 1 Spacelab payload were used to stimulate auroral emissions at southem auroral latitudes. The emitted electron beams were monoenergetic at $6.25 \mathrm{keV}$ and were fired in onesecond pulses every fifteen seconds with currents of $1.21 \mathrm{~A}$. Optical measurements of the beam were made in the vicinity of the Shuttle Orbiter by its on-board television camera and in the upper atmosphere by the Atmospheric Emissions Photometric Imager (AEPI). AEPI imaged auroral emissions in both white light and at the $427.8 \mathrm{~nm} \mathrm{~N}{ }_{2}{ }^{+}$emission line. Energy deposition calculations and the results of previous soundingrocket experiments had suggested that emissions with scale sizes of about 130 meters would result from the artificial electron beams with the visible emissions extending from about 110 to $130 \mathrm{~km}$ altitudes. In the ATLAS 1 experiments the auroral imaging was performed from the Shuttle, providing a new perspective on the artificial auroras and allowing the emissions to be traced from altitudes near the $295 \mathrm{~km}$ Shuttle altitude down to the $110 \mathrm{~km}$ level along the curved magnetic field lines.
\end{abstract}

\section{Introduction}

Gaining an understanding of Earth's natural aurora will require a multifaceted experimental and theoretical approach. The dynamical nature of the aurora and the tendency for many important phenomena to occur together have made it difficult to determine the relative roles of the magnetosphere and the ionosphere in triggering auroral displays and in determining the sources and closure of the field-aligned currents associated with them. A summary of contemporary problems that define auroral physics is provided in the book by Meng et al. [1991]. Measurements of the fields and plasmas associated with the aurora need to be made at higher temporal and spatial resolution, and ultimately at multiple locations simultaneously,

\footnotetext{
ISouthwest Research Institute, San Antonio, Texas

2Lockheed Palo Alto Research Laboratory, Palo Alto, California

${ }^{3}$ Institute of Space and Astronautical Science, Tokyo, Japan

${ }^{4}$ NASA, Marshall Space Flight Center, Alabama

${ }^{5}$ Nichols Research Corp., Arlington, Virginia

${ }^{6}$ University of Michigan, Ann Arbor, Michigan
}

Copyright 1993 by the American Geophysical Union.

Paper number 93GL00595

0094-8534/93/93GL-00595\$03.00 in order to characterize sufficiently the auroral particle acceleration processes. Of particular interest is the auroral acceleration region, which is located at altitudes of an Earth radius or so along the magnetic field lines threading the aurora; sounding rockets and satellites with increased capabilities are contributing significantly to the investigation of the auroral acceleration region. A complementary approach involves the use of artificial electron beams either to stimulate auroral displays in quiet regions where an unambiguous input-output experiment can be performed or to sense remotely auroral phenomena such as parallel electric fields as they occur naturally.

The Space Experiments with Particle Accelerators (SEPAC) were conducted as part of the ATLAS 1 Spacelab mission from March 24 through April 2, 1992. One of the objectives was to perform artificial aurora experiments from orbit using high-power electron beams and the optical imaging capability of the Atmospheric Emissions Photometric Imaging (AEPI) instrument [Mende et al., 1992]. The SEPAC electron beam accelerator (EBA) is capable of injecting electrons with beam energies up to $6.25 \mathrm{keV}$. At this energy the perveancelimited electron gun can emit beam currents of up to $1.21 \mathrm{~A}$, giving a beam power of $7.56 \mathrm{~kW}$. The previous flight of SEPAC on Spacelab 1 [Obayashi et al., 1984] showed that at these levels special means of neutralizing the Shuttle spacecraft are necessary; therefore, for ATLAS 1 the SEPAC instrument complement included three $122-\mathrm{cm}$ diameter conductive spheres for charge collection and a $1.6 \mathrm{~A}$ hollow-cathode $\mathrm{Xe}^{+}$ plasma contactor. The flight data show that the effectiveness of these charge neutralization devices was sufficient for injection of electron beams up to the highest beam currents available with the SEPAC EBA.

Artificial auroral experiments had been conducted previously from sounding rockets [Hess et al., 1971; Davis et al., 1971, 1980; O'Neil et al., 1979]. See also the comprehensive review by Winckler [1980]. The results of the previous experiments led to the expectation that the SEPAC EBA, at highest power, would produce an artificial aurora characterized by an emission with a diameter of about $130 \mathrm{~m}$ at altitudes of $110-130 \mathrm{~km}$. However, because of the favorable viewing geometry from orbit, the artificial aurora emissions produced by SEPAC on ATLAS I were imaged over the full extent of the curved magnetic field lines from near the Shuttle altitude of $295 \mathrm{~km}$ down to the $110-130 \mathrm{~km}$ altitude regime. Also present in the images were afterglows, which appeared as emission "tails" in the wake direction. Contrasts between SEPAC and the previous experiments include the facts that (1) the optical measurements were made from the same spacecraft from which the electron beam was injected rather than from the ground or aircraft, (2) effective charge neutralization was accomplished with the charge-collection spheres and the plasma contactor; and (3) the artificial auroras were produced in the auroral zone and in the neighborhood of natural auroras. 


\section{Experiment Description}

SEPAC is a joint U.S.-Japan investigation of the interaction of electron beams, plasma and neutral gas with the Earth's upper atmosphere, ionosphere and magnetosphere. It makes use of the large mass, volume and power capabilities of Shuttle/Spacelab as well as the interactive control that is possible through the involvement of payload and mission specialists. The first flight of SEPAC was with the Spacelab 1 mission (STS 9) in late November and early December 1983. Recenlly an upgraded instrument complement was included as part of the ATLAS 1 payload on STS-45 in late March and early April 1992. Table 1 shows the SEPAC instrument complement as flown on the ATLAS 1 payload.

During the artificial aurora experiments the plasma contactor (PC) was operated continuously so that up to $1.6 \mathrm{~A}$ of $\mathrm{Xe}^{+}$ions could be ejected to balance an equal current of electrons from the EBA. Since for ATLAS 1 the EBA current was limited to $1.21 \mathrm{~A}$, the $\mathrm{PC}$ had more than sufficient output current capability to maintain charge neutrality during the most intense electron beam injections. The neutralization process was aided by the charge collection spheres and the Shuttle conduclive surfaces (the engine bells and the inner surfaces of the payload bay doors), which can effectively collect ionospheric electrons along magnetic field lines.

Figure 1 demonstrates the ability of the plasma contactor and the conductive spheres to neutralize the Shuttle/Spacelab during electron beam injections. Figure 1 shows the spacecraft potential as measured by the three floating probes, the EBA current and voltage, and the PC current. The floating-probe data in Figure 1 show that the spacecraft potential did not rise more than about $5 \mathrm{~V}$ during the beam firings. By contrast, with no PC or conducting spheres on Spacelab 1, charging to the beam potential was observed when the beam current was above $100 \mathrm{~mA}$ [Burch, 1986].

Also providing evidence of spacecraft neutralization and of the fact that any beam-plasma instabilities or discharges did not disrupt the beam significantly during the artificial aurora experiment is the image of the beam in Figure 2. This image was taken in white light by the onboard low-light television system provided by the Shuttle Orbiter. The beam was not visible in the TV data except when neutral xenon was released from the PC. Figure 2 clearly shows the first spiral of the beam in the geomagnetic field as the beam was fired upward at $5 \mathrm{keV}$ and $500 \mathrm{~mA}$. The dark central segment of the straight section of the beam was produced by saturation of the TV camera, indicating the most intense part of the beam. The spiral in Figure 2 is located about 50 meters above the Shuttle. During this particular beam firing, magnetic deflection coils were used to deflect the beam by about $17^{\circ}$ to a pitch angle near $10^{\circ}$ resulting in the beam spiral. The divergence full angle of the beam itself was about $5^{\circ}$. It is possible that the injection of neutral xenon, which was required to make the beam visible to the Shuttle imager, modified the ambient environment and affected the threshold for certain beam-plasma interactions. During the artificial aurora experiments the neutral xenon injection was not employed.

\section{Artificial Aurora Experiment}

In each of the two artificial aurora experiments that were performed on ATLAS 1, twenty electron beam pulses were
Table 1. SEPAC Instrumentation for ATLAS 1

\begin{tabular}{|c|c|}
\hline Instrument/Parameter & Range \\
\hline \multicolumn{2}{|l|}{$\begin{array}{l}\text { Electron Beam Accelerator } \\
\text { (EBA) }\end{array}$} \\
\hline Energy & 0 to $6.25 \mathrm{keV}$ \\
\hline Current & 0 to $1.21 \mathrm{~A}$ \\
\hline Perveance & $2.5 \times 10^{-6} \mathrm{AV}^{-1.5}$ \\
\hline Initial Beam Diameter & $20 \mathrm{~mm}$ \\
\hline Deflection & 0 to $30^{\circ}$ from axis \\
\hline Modulation & $\leq 5 \mathrm{kHz}$ \\
\hline \multicolumn{2}{|l|}{$\begin{array}{l}\text { Xenon Plasma Contactor } \\
(P C)\end{array}$} \\
\hline $\begin{array}{l}\text { Ion-electron production } \\
\text { rate }\end{array}$ & $1.6 \mathrm{~A}$ \\
\hline Operation time available & 1500 hrs. \\
\hline Neutral gas pulse width & $100 \mathrm{~ms}$ (programmable) \\
\hline Number of ejected atoms & $\sim 6 \times 10^{22}$ per pulse \\
\hline \multicolumn{2}{|l|}{$\begin{array}{l}\text { Low-frequency plasma } \\
\text { wave probe }\end{array}$} \\
\hline Frequency & 0.75 to $10 \mathrm{kHz}$ \\
\hline \multicolumn{2}{|l|}{$\begin{array}{l}\text { High-frequency plasma } \\
\text { wave probe }\end{array}$} \\
\hline Frequency & 0.1 to $10.5 \mathrm{MHz}$ \\
\hline Wideband plasma wave & 0.4 to $10 \mathrm{kHz}$ \\
\hline probe & 0.1 to $4.2 \mathrm{MHz}$ \\
\hline Frequency & (or 4.0 to $7.5 \mathrm{MHz}$ ) \\
\hline \multicolumn{2}{|l|}{ Floating probes } \\
\hline Distances from pallet & $290 \mathrm{~mm}, 540 \mathrm{~mm}, 790 \mathrm{~mm}$ \\
\hline Frequency & 0 to $400 \mathrm{~Hz}$ \\
\hline Potential & $-8 \mathrm{kV}$ to $+8 \mathrm{kV}$ \\
\hline Resolution & $6 \mathrm{~V}$ \\
\hline \multicolumn{2}{|l|}{ Energetic Electron Analyzer } \\
\hline Energy & 0.1 to $15 \mathrm{keV}$ \\
\hline Energy resolution & $\Delta \mathrm{E} / \mathrm{E}=0.18$ \\
\hline Angular acceptance & $4^{\circ}$ by $10^{\circ}$ \\
\hline Sample rate & $100 \mathrm{~Hz}$ \\
\hline Energy sweep time & $320 \mathrm{~ms}$ \\
\hline \multicolumn{2}{|l|}{ Langmuir probe } \\
\hline Density & $10^{4}$ to $10^{8} \mathrm{e} \mathrm{cm}^{-3}$ \\
\hline Temperature & 600 to $5000 \% \mathrm{~K}$ \\
\hline Sample rate & $\begin{array}{l}1 \mathrm{kHz} \text { (current) } \\
250 \mathrm{~Hz} \text { (voltage) }\end{array}$ \\
\hline \multicolumn{2}{|l|}{ lonization gauge } \\
\hline Pressure range & $5 \times 10^{-8}$ to $5 \times 10^{-4}$ Tor \\
\hline Sample rate & $1 \mathrm{kHz}$ \\
\hline
\end{tabular}

injected downward from an altitude of $295 \mathrm{~km}$ with $0^{\circ}$ pitch angle at relatively high southern magnetic latitudes $\left(65-67^{\circ}\right)$. During the experiments, optical observations were made with the AEPI instrumentation. In the first experiment white-light images were acquired at a rate of $30 \mathrm{~Hz}$, while in the second experiment these high-rate white-light images were supplemented by images at $427.8 \mathrm{~nm}$, which were integrated over 1 second. The $427.8 \mathrm{~nm} \mathrm{~N}{ }^{+}$line was chosen because it is a prompt emission with a well-known relationship to total precipitating electron energy flux. The electron beam pulses were injected once every 15 seconds at the maximum energy and current $(6.25 \mathrm{keV}, 1.21 \mathrm{~A})$ with pulse widths of 1 second.

Figure 3 shows two consecutive $427.8 \mathrm{~nm}$ images that were obtained 30 seconds apart in the southern auroral zone during the second artificial aurora experiment. High-timeresolution white-light images of the artificial aurora are discussed by Mende [1992]. In Figure 3a the artificial aurora 


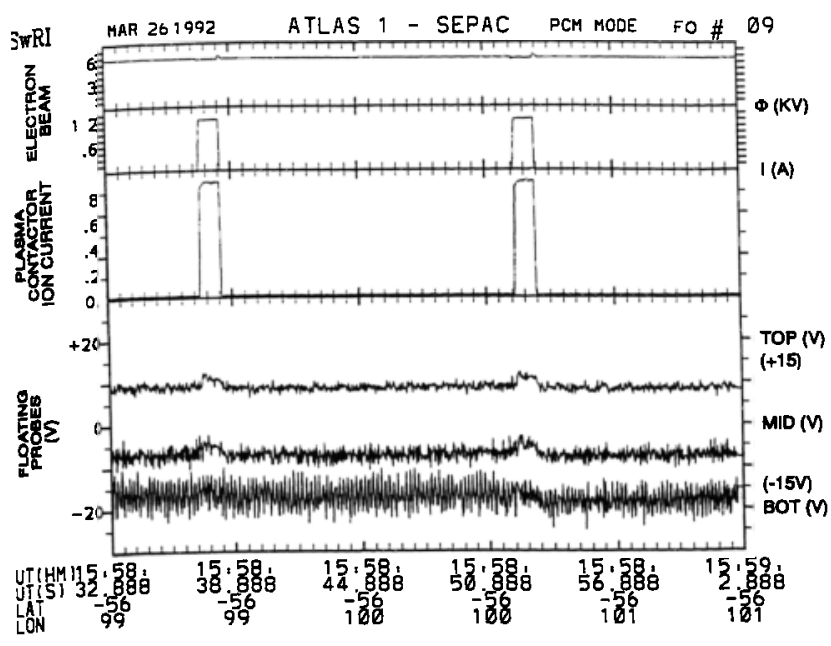

Fig. 1. A 30-second plot of the EBA voltage and current, the $\mathrm{PC}$ ion current, and the three floating-probe potentials in the top to bottom panels, respectively. The PC ion current is plotted in normalized units pending final monitor calibration. The floating-probe potential traces are separated by $15 \mathrm{~V}$ to avoid overlap.

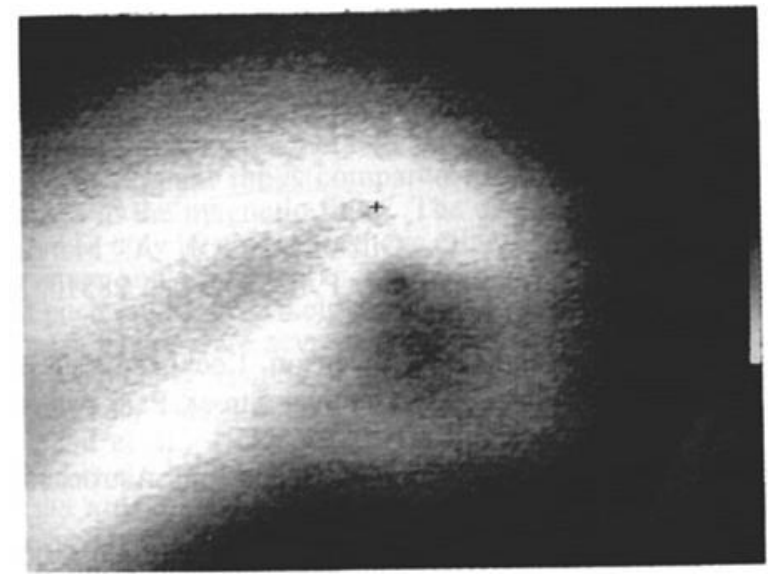

Fig. 2. Image from an Orbiter payload-bay television camera $\left(40^{\circ}\right.$ horizontal field of view) of a SEPAC artificial electron beam with energy of $5 \mathrm{keV}$ and current of $500 \mathrm{~mA}$. The beam was rendered visible by the injection of a neutral Xe pulse (see Table 1), which was excited by the electron beam. The dark central region of the straight section of the beam is a saturation effect. The first spiral of the beam in the Earth's magnetic field, which is evident near the end of the visible beam in the right-hand side of the figure, was located about 50 meters above the Orbiter. The illuminated object in the lower righthand corner of the image is part of the payload bay instrumentation.

is located in the dark region near a quiet auroral arc, while in Figure $3 \mathrm{~b}$ the artificial aurora is superimposed upon a naturally occurring quiet auroral arc. Each artificial aurora image contains significant spatial structure, the most persistent features being a tapered extension toward the bottom of the image and (particularly noticeable in Figure 3a) a trail in the Shuttle wake direction, possibly indicating an afterglow phenomenon. The travel time of the beam to the $110 \mathrm{~km}$ level is only about $5 \mathrm{~ms}$, and the $427.8 \mathrm{~nm}$ emission is prompt, with a lifetime of $<1 \mu \mathrm{s}$; therefore, the wake trail was not predicted. The afterglow present in the wake trail may have been produced by induced electron precipitation, caused perhaps by an enhancement of ionospheric Pederson conductivity produced by the artificial beams, although this possibility needs to be investigated further. Another possibility is the acceleration of ambient electrons by beam-plasma interactions that may have persisted for several tens of ms after the electron beam moved out of an excited magnetic flux tube, as suggested by Wilhelm et al. [1985].

The tapered extensions toward the bottom of the images in Figures $3 a$ and $3 b$ are produced by the curvature of the
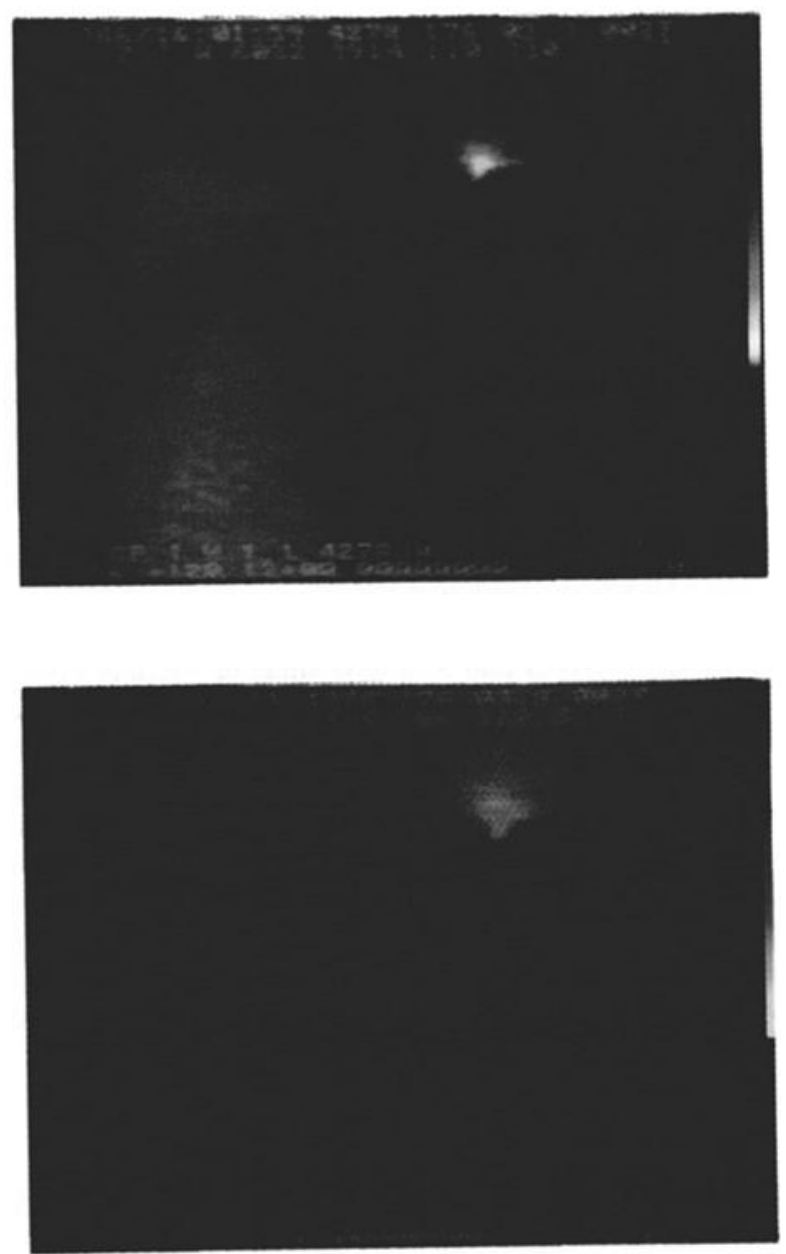

Fig. 3. (a) Artificial aurora image in $427.8 \mathrm{~nm}$. To the left is a quiet auroral arc; in the upper right is the artificial aurora. The image was obtained by the AEPI instrument [Mende et al., 1992], which viewed downward along the magnetic field direction, during a one-second period beginning at 16:01:59 UT on March 26, 1992. The direction of motion of the Shuttle Orbiter was to the left, so the natural auroral arc is broadened in the horizontal direction by about $10 \%$. The width of the image at the $110-\mathrm{km}$ level is about $80 \mathrm{~km}$. The color bar is linear from top to bottom and extends from 0 to about $5 \mathrm{kR}$. (b) Same as (a) except that in this case the image was obtained over the one-second period beginning at 16:02:29 UT on March 26, 1992, and the artificial aurora was superimposed upon a somewhat weaker quiet auroral arc. 
magnetic field line. For this experiment the Shuttle was moving generally eastward, or to the left in figures $3 a$ and $3 b$, so south and north are toward the top and bottom of the figures, respectively. The AEPI has a field of view of $20^{\circ}$, so at $110 \mathrm{~km}$ the width of the images in Figure 3 is about $80 \mathrm{~km}$. The displacement of a dipole field line at a magnetic latitude of $65^{\circ}$ between $295 \mathrm{~km}$ and $110 \mathrm{~km}$ because of field-line curvature is about $1.8 \mathrm{~km}$, which is consistent with the images in Figure 3. The bottom tip of the downward tapered extensions in Figure 3 is, then, the lower extension of the artificial aurora at altitudes of about $110 \mathrm{~km}$. Detailed analysis of the images is reported by Mende et al. [1992].

Future experiments are needed to take advantage of the much greater detectability of the artificial aurora emissions from orbit in performing more extensive spectral analyses and in using the artificial electron beams to sense remotely electric fields in the auroral zone. For example, the use of an oxygen emission line (such as $630.0 \mathrm{~nm}$ ) along with the nitrogen line would help determine the altitude profile of the artificial aurora. In addition, the fact that the artificial auroras are easily detectable even when superimposed on bright natural auroras supports the possibility that upward-propagating electron beams, reflected by parallel electric fields above the aurora, would produce detectable artificial auroras, which could be used to map the strength and spatial distributions of the parallel E-fields.

Acknowledgements. Many people have contributed to the SEPAC experiment over the years. Professor Tatsuzo Obayashi, who is recently deceased, was the original principal investigator beginning in 1976. Bill Tomlinson and George Ferguson of SwRI and Randy Bounds of Nichols Research contributed extensively to the hardware and software efforts. At ISAS numerous scientists and engineers contributed to SEPAC, including Drs. K. Kuriki, M. Nagatomo, K. Ninomiya, and $M$. Ejiri. We have benefitted greatly from the involvement of co-investigators Drs. Rick Chappell and Peter Banks; the ATLAS 1 crew; the ATLAS Project personnel, under the guidance of Tony O'Neill of MSFC, and Dr. Bob Beattie of Hughes Research Laboratory. This work was supported by NASA Contracts NAS8-32488 and NAS832827 with SwRI.

\section{References}

Burch, J. L., Space plasma physics results from Spacelab, $J$. Spacecraft and Rockets, 23, 331-335, 1986.

Davis, T. N., et al., Artificial aurora experiment: ground- based optical observation, J. Geophys. Res., 76, 6082 6092, 1971.

Davis, T. N., et al., Artificial aurora conjugate to a rocketborne electron accelerator, J. Geophys. Res., 85, 1722$1728,1980$.

Hess, W. N., et al., Artificial auroral experiment: experiment and principal results, J. Geophys. Res., 76, 6067-6081, 1971.

Mende et al., Artificial auroras in the upper atmosphere: 2. imaging results, Geophys. Res. Lett., this issue, 1992.

Meng, C.-I., M. J. Rycroft, and L. A. Frank, Auroral Physics, Cambridge University Press, Cambridge, 1991.

Obayashi, T., et al., Space experiments with particle accelerators, Science, 225, 195-196, 1984.

O'Neil, R. R., E. T. P. Lee, and E. R. Huppi, Auroral O('s) production and loss processes: ground-based measurements of the artificial auroral experiment Precede, J. Geophys. Res., 84, 823-833, 1979.

Rees, M. H., G. J. Romick, H. R. Anderson, and R. T. Casserly, Jr., Calculation of auroral emissions from measured electron precipitation: comparison with observation, J. Geophys. Res., 81, 5091-5096, 1976.

Wilhelm, K., W. Bernstein, P. J. Kellogg, and B. A. Whalen, Fast magnetospheric echoes of energetic electron beams, J. Geophys. Res., 90, 491-504, 1985.

Winckler, J. R., The application of artificial electron beams to magnetospheric research, Rev. Geophys. Space Phys., $18,659-682,1980$.

J. L. Burch, W. C. Gibson, and J. A. Marshall, Southwest Research Institute, P. O. Drawer 28510, San Antonio, TX 78228-0510.

S. B. Mende and G. R. Swenson, Lockheed Palo Alto Research Laboratory, 3257 Hanover Street, Palo Alto, CA 94304.

N. Kawashima, Institute of Space and Astronautical Science, Sagamihara, Kanagawa 172, Japan.

W. T. Roberts, PS02, Marshall Space Flight Center, Alabama 35812.

W. W. L. Taylor, Nichols Research Corp., $1700 \mathrm{~N}$. Moore St, Arlington, VA 22209.

T. Neubert, Space Physics Research Laboratory, University of Michigan, Ann Arbor, MI 48109.

(Received: September 21, 1992;

revised: January 28, 1993; accepted: January 29, 1993) 